\title{
Tác động của Covid-19 đến tình trạng biến đổi khí hậu và các chính sách chống biến đổi khí hậu.
}

\author{
Bùi Phương Linh, Thân Mai Huyền, Đinh Thùy Linh, \\ Lê Tùng Lâm, Trần Lan Hương
}

Đại học Quốc gia Hà Nội

Ngày 28 tháng 01 năm 2022

Preprint DOI:

\section{Thực trạng}

Hiện nay, toàn nhân loại chúng ta đang phải trải qua một thời kỳ vô cùng đen tối và chưa từng có tiền lệ trong lịch sử, thời kỳ “Đại dịch Covid-19". Dịch bệnh đã khiến đa số các quốc gia trên thế giới phải áp dụng chính sách giãn cách xã hội, hạn chế đi lại và ở yên trong nhà (La, 2020). Lúc này, các hoạt động di chuyển cũng như việc vận hành, sản xuất của một số xí nghiệp bị tạm ngưng và khí thải từ các phương tiện giao thông, các nhà máy xả ra không khí giảm thiểu đáng kể. Và ít khói bụi từ đường phố hơn so với khi chưa giãn cách đã khiến chúng ta có suy nghĩ rằng không khí xung quanh ta đã dần hết ô nhiễm và trở nên trong lành hơn. Từ đó mà một câu hỏi được đặt ra rằng: Liệu Covid-19 có làm cho bầu trời của chúng ta trong xanh hơn ?

\section{Tác động của Covid-19 đến tình trạng biến đổi khí hậu.}

\section{Tác động đến lự̣ng khí thải toàn cầu.}

Một nghiên cứu được công bố vào tháng 5 năm 2020 cho thấy lượng phát thải carbon toàn cầu hàng ngày trong giai đoạn phong tỏa vào đầu tháng 4 đã giảm $17 \%$ và có thể dẫn đến giảm lượng khí thải carbon hàng năm lên tới $7 \%$, đó sẽ là sự sụt giảm lớn nhất kể từ Thế chiến II theo các nhà nghiên cứu. Họ gán cho những sụt 
giảm này chủ yếu là do giảm các hoạt động sử dụng và công nghiệp vận chuyển. Tuy nhiên, người ta đã lưu ý rằng sự hồi phục sau dịch sẽ xóa chênh lệch giảm bớt này do các hoạt động công nghiệp hạn chế hơn (Anh, 2021).

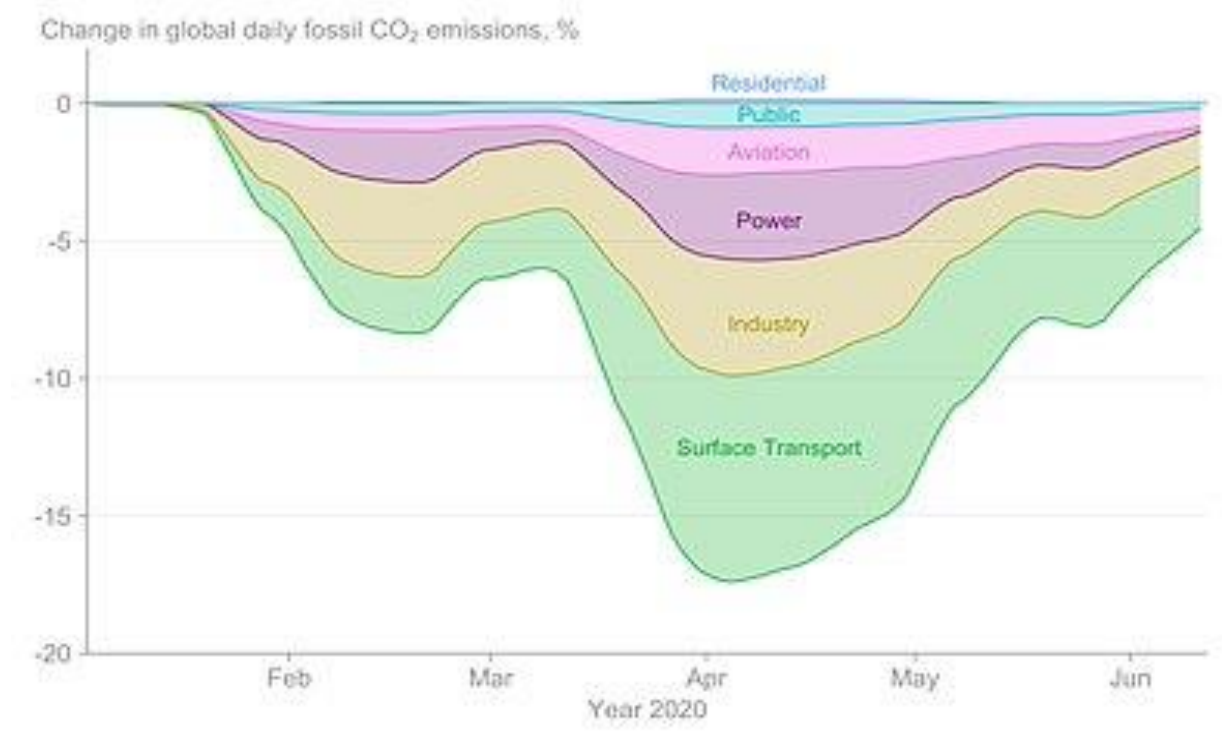

Hình 1. Thay đổi về lương khí thải $\mathrm{CO}_{2}$ hóa thạch hàng ngày trên toàn cầu trong đại dịch COVID-19 trong năm 2020 ( nguồn: internet ) https://vi.wikipedia.org/wiki/\%E1\%BA\%A2nh_h\%C6\%B0\%E1\%BB\%9Fng_c\%E1\%BB\%A7a_ $\% \mathrm{C} 4 \% 91 \% \mathrm{E} 1 \% \mathrm{BA} \% \mathrm{~A} 1 \mathrm{i}$ d\%E1\%BB\%8Bch_COVID19_\%C4\%91\%E1\%BB\%91i_v\%E1\%BB\%9Bi_m\%C3\%B4i_tr\%C6\%B0\%E1\%BB\%9Dng

Bằng cách nhập dữ liệu từ nhiều vệ tinh trong năm 2020 vào 4 mô hình dự đoán phản ứng khí quyển, các nhà nghiên cứu tại NASA phát hiện lượng khí thải NOx dao động lên xuống với cường độ có liên quan tới các sự kiện cách ly. Trong tháng 4 và 5 , tượng khí thải toàn cầu giảm ít nhất $15 \%$. Các nước có chính sách cách ly gắt gao nhất rõ ràng có lượng giảm thải cao nhất. Ví dụ, ở Trung Quốc, lệnh cách ly ban hành từ đầu năm đã giúp quốc gia này giảm tới $50 \%$ lượng khí thải. Ở các khu vực áp dụng chính sách cách ly sau đó như Mỹ, châu Âu, Trung Đông, Tây Á, lượng khí thải NOx giảm khoảng 18\% đến 25\% trong tháng bốn và năm (Hải, 2021). 


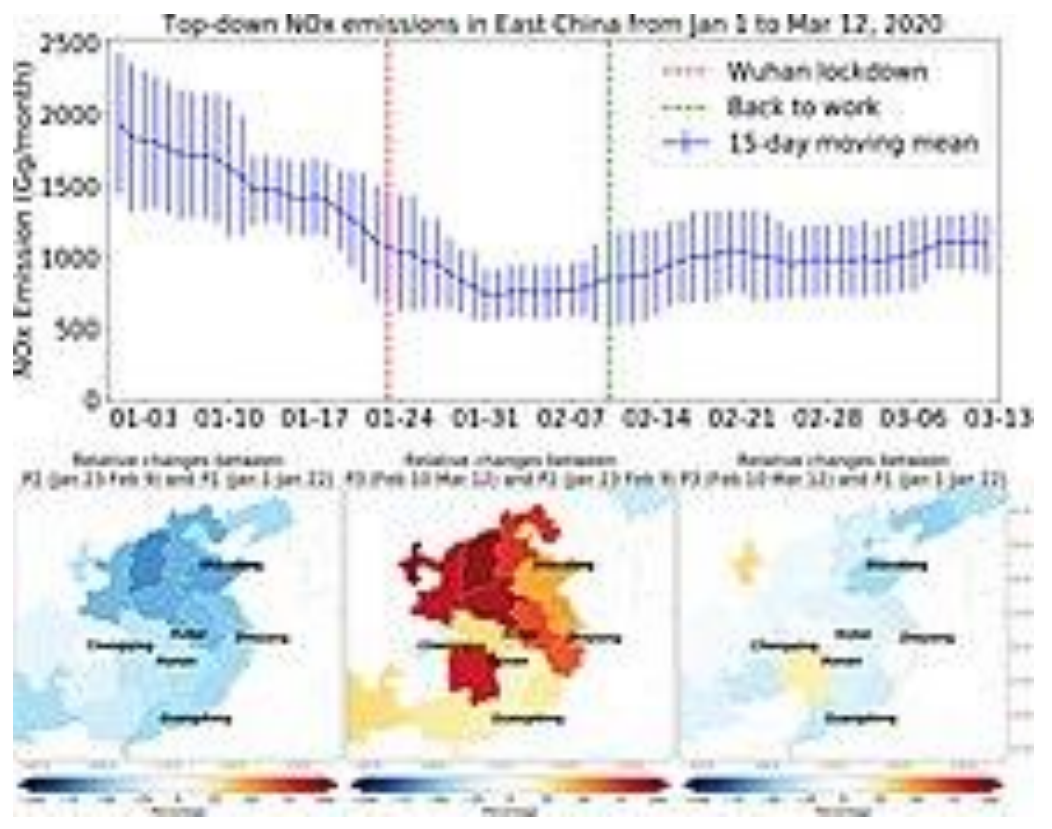

Hình 2. Thay đổi phát thải NOx ở Đông Trung Quốc (nguồn: internet)

https://vi.wikipedia.org/wiki/\%E1\%BA\%A2nh h\%C6\%B0\%E1\%BB\%9Fng_c\%E1\%BB\%A7a $\% \mathrm{C} 4 \% 91 \% \mathrm{E} 1 \% \mathrm{BA} \% \mathrm{A1i} \mathrm{d} \% \mathrm{E} 1 \% \mathrm{BB} \% 8 \mathrm{Bch} \_\mathrm{COVID}-$

19_\%C4\%91\%E1\%BB\%91i_v\%E1\%BB\%9Bi_m\%C3\%B4i_tr\%C6\%B0\%E1\%BB\%9Dng

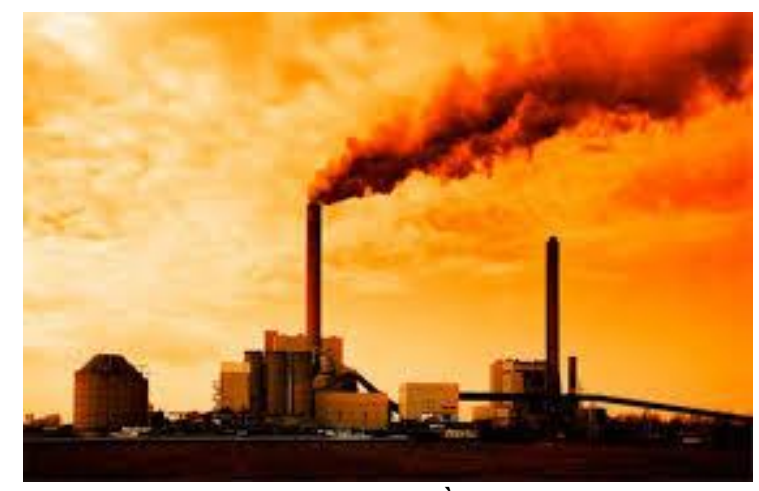

Hình 3. Lương khí thải metan toàn cầu tang vọt lên múc cao kỷ lục ( nguồn: internet)

https://rama.com.vn/luong-khi-thai-metan-toan-cau-tang-vot-len-muc-cao-ky-luc/

Trong khi lượng khí thải carbon giảm trong đại dịch, lượng khí thải mêtan do chăn nuôi vẫn tiếp tục tăng.

\section{Tác động đến tầng ozone}


Các ước tính mới của NASA cho thấy mức độ ô nhiễm tầng ozone trong tháng 5 và 6 năm 2020 giảm 2\%, phần lớn do giảm khí thải tại khu vực Châu Á và Mỹ (Anh, 2021). Điều này nghe có vẻ không nhiều, nhưng các chuyên gia cho rằng mức giảm tương đương với ít nhất 15 năm áp dụng các chính sách giảm phát thải tốt nhất do Ủy ban liên chính phủ về biến đổi khí hậu đưa ra.

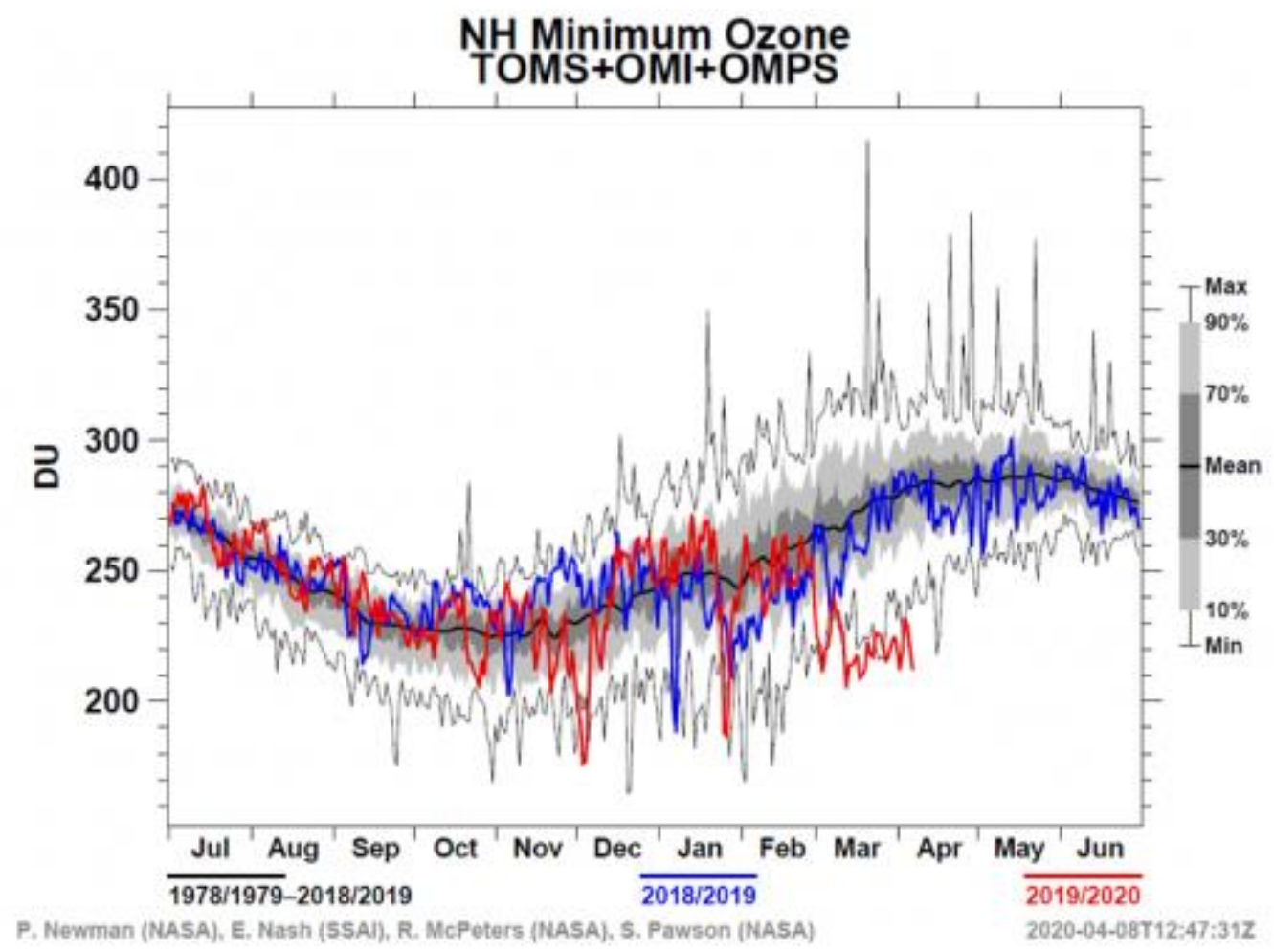

Hình 4. Thống kê dũ liệu về tầng ozone trong giai đoạn 2019-2020

( nguồn: WMO )

http://vnmha.gov.vn/tin-tuc-bdkh-112/su-suy-giam-tang-ozone-dang-dat-muc-ky-luc-6806.html

\section{Tác động đến hiện tự̆ng ấm lên toàn cầu}

Nhiệt độ trung bình toàn cầu hiện tại tiếp tục cao hơn $1^{\circ} \mathrm{C}$ so với thời kỳ tiền công nghiệp và dự kiến sẽ tiếp tục tăng lên ngưỡng quan trọng là $1,5^{\circ} \mathrm{C}$ trong 5 năm tới.

Riêng năm nay, nhiệt độ ở hầu hết các khu vực ở Bắc bán cầu sẽ cao hơn 0,8 độ $\mathrm{C}$ so với vài thập kỷ trước, và khu vực Tây Nam nước Mỹ sẽ tiếp tục khô cằn. 
Điều đáng chú ý là Randall Cerveny, một nhà khoa học khí hậu và báo cáo viên của WMO tại Đại học Bang Arizona, tuyên bố rằng dịch Covid-19 được kỳ vọng sẽ giúp giảm bớt sự nóng lên toàn cầu do các hoạt động du lịch. Sản xuất công nghiệp bị gián đoạn - nhưng không phải vậy.

Tổng thư ký WMO Petteri Taalas nhấn mạnh, kết quả của báo cáo đã gióng lên hồi chuông cảnh báo, kêu gọi thế giới giảm phát thải khí nhà kính và đạt được mức độ trung tính carbon càng sớm càng tốt. Đồng thời, Liên hợp quốc cảnh báo rằng vào cuối năm 2020 , người dân trên thế giới dự kiến sẽ khiến trái đất nóng lên vượt quá 3 độ $\mathrm{C}$ vào cuối thế kỷ này (Mai, 2021).

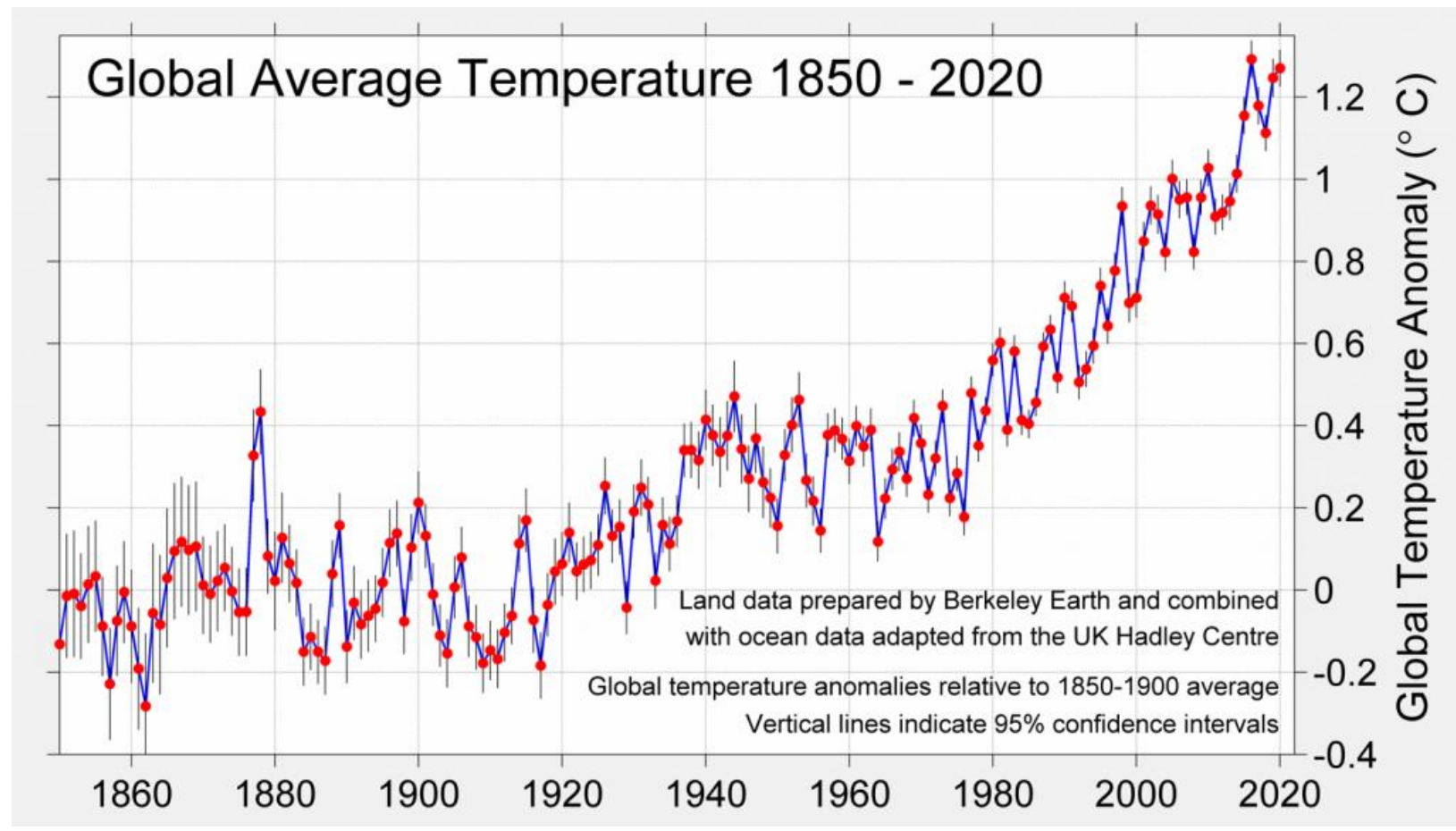

Hình 5. Nhiệt độ trung bình toàn cầu vào năm 2020 được ước tính là cao hơn $1,27^{\circ} \mathrm{C}\left(2,29^{\circ} \mathrm{F}\right)$ so với nhiệt độ trung bình của cuối thế kỷ 19

( nguồn: Robert Rohde. Global Temperature Report for 2020 - Berkeley Earth)

http://berkeleyearth.org/global-temperature-report-for-2020/

\section{Nhận xét}

Tình trạng biến đổi khí hậu trên thế giới nói chung và Việt Nam nói riêng vẫn đang có những diễn biến hết sức căng thẳng. Đến thời kì đại dịch Covid-19, nhiều nơi áp dụng các chính sách giãn cách xã hội từ đó hạn chế hoạt động di chuyển, phát thải của con người. Nhờ những chính sách này, tình trạng biến đổi khí hậu đã có 
những dấu hiệu thay đổi tích cực. Trước những chuyển biến ấy, nhiều người đã đặt ra câu hỏi liệu Covid-19 có đang khiến bầu trời của chúng ta trong xanh hơn không?

Qua những nghiên cứu được nêu trên, chúng ta thấy rằng Covid-19 không làm cho bầu trời trong xanh hơn. Dịch bệnh khiến chúng ta phải thực hiện giãn cách xã hội và ở yên trong nhà, lúc này các hoạt động đi lại bị tạm dừng và khí thải từ các phương tiện giao thông xả ra không khí giảm thiểu đáng kể khiến cho chúng ta cảm thấy bầu trời trong xanh hơn nhưng thực chất qua các nghiên cứu, dẫn chứng cụ thể thì biểu hiện trên chỉ mang tính chất tạm thời. Do đó, để có thể cải thiện vấn đề biến đổi khí hậu thực sự thì chúng ta cần phải thực hiện các hành động mang tính khả thi hơn. Bây giờ chúng ta hãy thử làm một phép so sánh về con số thương vong giữa đại dịch Covid-19 tính đến cuối năm 2020 và cơn lũ lịch sử cũng xảy ra trong năm đó tại Việt Nam. Số ca tử vong do Covid-19 tính đến cuối năm 2020 là 35 ca trong khi trong khi thiên tai chỉ trong tháng 10 và 11 đã gây thương vong đến trên 250 người. Bên cạnh đó, Các biện pháp kiểm soát đại dịch đã gây ra tổn thất kinh tế đáng kể trong năm 2020, dự kiến làm giảm $4,2 \%$ tăng trưởng GDP so với quỹ đạo kinh tế trước khi có vi-rút cô-rô-na. Trong khi đó, thiệt hại kinh tế do bão gây ra ước rơi vào khoảng 1,3 tỷ USD, hay khoảng $0,5 \%$ GDP. So sánh này không phải chỉ ra vấn đề nào là nguy cơ nghiêm trọng hơn mà chỉ ra một thắc mắc: Vì sao Việt Nam chưa giải quyết hiệu quả các vấn đề về môi trường và khí hậu như khi giải quyết các vấn đề liên quan đến đại dịch Covid-19? Có người nói rằng hậu quả của Covid-19 diễn ra ngay lập tức còn ô nhiễm môi trường thì không như vậy. Nhưng thực ra chúng ta hiện nay đã phải hứng chịu các hậu quả từ ô nhiễm môi trường, biến đổi khí hậu như các cơn bão với tần suất và cương độ ngày càng lớn hay ô nhiễm không khí là một nguyên nhân gây tử vong cho 60.000 mỗi năm, theo Tổ chức Y tế thế giới (WHO) (Morisset, 2020). Bài học rút ra từ đây chính là chính phủ Việt Nam nói chung và chính phủ các quốc gia khác trên thế giới cần luôn trong trạng thái sẵn sàng để đối mặt và giải quyết các vấn đề liên quan đến môi trường, hành động ngay từ bây giờ, đưa ra các biện pháp cụ thể, thiết thực để "tiêu diệt" các vấn đề về môi trường, biến đổi khí hậu.

Nhìn chung, "đại dịch" Covid-19 không làm ảnh hưởng nhiều đến sự biến đổi khí hậu mà nó chỉ tạm thời giảm bớt các khí thải từ quá trình hoạt động và đi lại của con người. Những tác động này không làm cho khí hậu trái đất thay đổi đáng kể và chúng cũng không mang lại hiệu quả bền vững, lâu dài. Đại dịch Covid nổ ra như một hồi chuông cảnh báo con người phải có những biện pháp cấp bách và hiệu quả để ứng phó với biến đổi khí hậu. Việt Nam nói chung và toàn cầu nói riêng vẫn đang trong quá trình nỗ lực để khôi phục và bảo vệ màu xanh của Trái đất. 


\section{Các chính sách chống biến đổi khí hậu}

\section{Tăng cuờng sụ hợp tác giữa các quốc gia}

Để giảm thiểu những tác động tiêu cực do biến đổi khí hậu gây nên, thế giới đã tăng cường hợp tác và cùng nhau hành động thực chất, đưa ra những chiến lược hợp tác với lộ trình, công cụ hữu hiệu để vượt qua những thách thức này (Vuong, Q.H., 2022). Các phiên họp và hội nghị đàm phán về chống biến đổi khí hậu mang quy mô toàn cầu được tổ chức thường niên với nỗ lực cùng chung tay chống lại biến đổi khí hậu. Năm 1988, Tổ chức Khí tượng Thế giới (WMO) và Chương trình Môi trường Liên hợp quốc (UNEP) thành lập Ủy ban Liên chính phủ về Biến đổi Khí hậu (IPCC), một cơ quan chuyên gia đánh giá thông tin khoa học về biến đổi khí hậu. Để phản ứng lại những quan ngại được nêu ra trong Báo cáo Đánh giá Đầu tiên của IPCC, Đại hội đồng Liên Hợp Quốc đã thành lập Ủy ban Đàm phán Liên Chính phủ về Công ước Khung về Biến đổi Khí hậu. Công ước khung của Liên hợp quốc về biến đổi khí hậu (UNFCCC) được thông qua vào tháng 5 năm 1992 và có hiệu lực từ năm 1994. Công ước bao gồm cam kết ổn định phát thải khí nhà kính ở mức 1990 vào năm 2000. Công ước đầu tiên của các bên tham gia UNFCCC (COP 1) được tổ chức vào năm 1995. Các cuộc đàm phán tại đây và hai COP tiếp theo đã dẫn đến thống nhất về Nghị định thư Kyoto vào năm 1997. Nghị định thư Kyoto đưa ra các cam kết cụ thể của các nước phát triển riêng lẻ nhằm giảm lượng khí thải bằng cách trung bình thấp hơn 5,2\% so với mức của năm 1990 trong giai đoạn 2008-2012 (BBT, 2021).

Gần đây nhất là hội nghị COP 26 được tổ chức với mục tiêu giảm phát thải khí nhà kính và thích ứng với biến đổi khí hậu; xây dựng hướng dẫn thực hiện đối với một số điều khoản quan trọng còn lại của Thỏa thuận Paris; huy động đủ 100 tỷ USD/năm để tài trợ cho các hoạt động ứng phó với BĐKH tại các nước đang phát triển và nhất trí được về cách thức xác định trước năm 2025 mục tiêu tài chính mới cho giai đoạn sau năm 2025 (TTXVN, 2021). Hội nghị kết thúc vào ngày 13 tháng 11 năm 2021 tại Glasgow, Anh. Gần 200 quốc gia đã đồng ý Hiệp ước Khí hậu Glasgow để duy trì mục tiêu kiểm soát nhiệt độ tăng ở mức $1,5^{\circ} \mathrm{C}$, và cuối cùng hoàn thành phần chưa được giải quyết của Thỏa thuận Paris.

\section{Khuyến khích người tiêu dùng}


Tuyên truyền, khuyến khích mọi người hạn chế sử dụng nhiên liệu hóa thạch và giảm lượng khí thải carbon của họ.

\section{Các chính sách định giá carbon}

Yêu cầu người phát thải phải trả tiền cho lượng khí thải carbon của họ, chẳng hạn như thuế carbon (sẽ yêu cầu người phát thải phải trả thuế cho mỗi tấn carbon mà họ thải ra) hoặc chương trình định mức và thương mại (sẽ yêu cầu các doanh nghiệp đăng ký để có giấy phép cho mỗi tấn carbon mà họ thải ra).

\section{Yêu cầu tăng cuờng chất luọng sản phẩm}

Đưa ra các quy định cũng như các chính sách ưu đãi thuế nhằm khuyến khích các nhà sản xuất tăng cường hiệu quả sử dụng năng lượng cho các sản phẩm của họ, bao gồm ô tô, thiết bị và tòa nhà. Điều này cho phép nhà sản xuất tận dụng một cách tối đa nguồn năng lượng mà không để lãng phí, tiết kiệm nguồn chi phí hơn.

\section{Chuyển sản xuất điện sang năng lự̣ng tái tạo}

Nguồn năng lượng tái tạo có tiềm năng để thay thế nguồn năng lượng từ nhiên liệu hóa thạch và hạt nhân. Ngoài ra, vì nguồn cung cấp gần như không giới hạn, nó sẽ tránh bị cạn kiệt dần sau một thời gian dài hoạt động giống như các nguồn nhiên liệu hóa thạch ngày nay như than, dầu mỏ, khí đốt, khí tự nhiên v.v...

\section{6. Đầu tư vào hệ thống giao thông công cộng}

Giảm phát thải khí nhà kính bằng việc giảm thiểu việc đi lại bằng các phương tiện cá nhân như ôtô, xe máy và tăng cường phát triển mạng lưới giao thông công cộng với các phương tiện sử dụng năng lượng sạch như tàu điện, xe buýt điện v.v... Điều này còn góp phần làm giảm tình trạng ách tắc giao thông tại các đô thị lớn vào những giờ cao điểm, giúp làm đẹp cảnh quan thành phố hơn.

\section{7. Úng dụng khoa học và công nghệ cao vào đò̀i sống sản xuất}


Tập trung đầu tư vào khoa học công nghệ (Q. H. Vuong, 2018), phát triển ngành công nghiệp sạch, ứng dụng công nghệ cao, loại bỏ dần và thay thế dần phương thức sản xuất công nghiệp cũ, lạc hậu gây ô nhiễm môi trường.

\section{Thúc đẩy phát triển du lịch xanh - sạch - đẹp}

Tận dụng lợi thế của từng khu vực để đưa du lịch trở thành ngành kinh tế mũi nhọn, đặc biệt chú ý đến thu hút khách du lịch tham gia bảo vệ môi trường, đa dạng sinh học của các sinh cảnh địa phương quý giá (Krosnick \& MacInnis, 2020).

\section{Xây dựng văn hóa môi trường}

Sử dụng hệ xử lý thông tin 3D, nguyên lý bán dẫn và khung văn hóa để xây dựng văn hóa môi trường. Đây là giải pháp căn cơ gốc rễ để giúp con người hành động vì môi trường với giá trị cốt lõi là thặng dư sinh thái (Khuc, 2021; Q.-H. Vuong, 2021; Q. H. Vuong, 2021; Q. H. Vuong \& Napier, 2014).

\section{Kết Luận}

Như vậy, dịch bệnh Covid-19 không giúp ích trực tiếp cho môi trường và khí hậu của chúng ta như mọi người vẫn lầm tưởng. Chính sách giãn cách xã hội chỉ làm giảm một lượng rất nhỏ khí carbon dioxide từ phương tiện giao thông chứ không làm cải thiện hoàn toàn vấn đề ô nhiễm môi trường không khí, bởi kể cả trong thời kỳ đại dịch, thế giới vẫn đang ghi nhận mức tăng cao của nhiệt độ trên toàn thế giới, dự báo tới "một ngày tận thế" không còn xa với nhân loại nếu chúng ta không có biện pháp khắc phục tình trạng này. Tuy nhiên, không thể phủ nhận rằng nhờ Covid19 mà chúng ta đã có cơ hội ngồi xuống và cùng nhìn nhận lại các vấn đề về môi trường đang vô cùng nghiêm trọng, cùng nhau đưa ra những phương pháp, hướng giải quyết phù hợp, thiết thực hơn. Covid-19 có thể phần nào bị ngăn chặn thông qua ý thức của con người và điều này cũng sẽ đúng đối với môi trường. Môi trường của chúng ta sẽ được cứu nhờ vào ý thức từ chính bản thân chúng ta. "Cứu Trái đất cũng chính là cứu chính mình".

\section{Tài liệu tham khảo}


Anh, T. (2021). Đại Dịch Covid-19 Và Những Tác Động Đến Môi Trường. Tạp Chí Mặt Trận Online. http://tapchimattran.vn/the-gioi/dai-dich-covid19-vanhung-tac-dong-den-moi-truong-40037.html

BBT. (2021). Policy Responses to Climate Change. World Nuclear Association. http://world-nuclear.org/information-library/energy-and-theenvironment/policy-responses-to-climate-change.aspx

Hải, N. (2021). Ích Lợi Bất Ngò̀ Tù Đại Dịch: Tầng Ozone Hồi Phục Nhanh Hơn Dự Kiến 15 Năm. Cục Biến Đổi Khí Hậu - Bộ Tài Nguyên và Môi Trường. http://www.dcc.gov.vn/tin-tuc/3725/Ich-loi-bat-ngo-tu-dai-dich:-Tang-ozonehôi-phuc-nhanh-hon-du-kien-15-nam.html

Khuc, Q. Van. (2021). Khucc tower: from cultural values to practical solutions. Working Paper, 2021.

Krosnick, J. A., \& MacInnis, B. (2020). Climate Insights 2020: Policies And Politics. https://www.rff.org/publications/reports/climateinsights2020-policiesand-politics/

La, V. P. et al. (2020). Policy response, social media and science journalism for the sustainability of the public health system amid the COVID-19 outbreak: The vietnam lessons. Sustainability (Switzerland), 12(7). https://doi.org/10.3390/su12072931

Mai, X. (2021). Covid-19 Không Thể Ngăn Biến Đổi Khí Hậu. Người Lao Động. https://nld.com.vn/thoi-su-quoc-te/covid-19-khong-the-ngan-bien-doi-khi-hau20210527215037091.htm

Morisset, J. (2020). JUST DO IT - Vietnam Can Learn From COVID-19 To Address Its Environment And Climate Challenge. World Bank Blogs. https://blogs.worldbank.org/eastasiapacific/just-do-it-vietnam-can-learn-covid19-address-its-environment-and-climate-challenge

TTXVN. (2021). Nhũng Nội Dung Chính Của Hội Nghị COP26. Infographics Tin Đồ Họa. https://infographics.vn/nhung-noi-dung-chinh-cua-hoi-nghicop26/42011.vna

Vuong, Q.H., et al. (2022). Covid-19 vaccines production and societal immunization under the serendipity-mindsponge-3D knowledge management theory and conceptual framework. Humanities \& Social Sciences Communications, 9, 22. Retrieved from: https://www.nature.com/articles/s41599-022-01034-6

Vuong, Q.-H. (2021). Western monopoly of climate science is creating an eco- 
deficit culture. Economy, Land \& Climate Insight, 11, 1-9. https://elcinsight.org/western-monopoly-of-climat

Vuong, Q. H. (2018). The (ir)rational consideration of the cost of science in transition economies. Nature Human Behaviour, 2(1), 5. https://doi.org/10.1038/s41562-017-0281-4

Vuong, Q. H. (2021). The semiconducting principle of monetary and environmental values exchange. Economics and Business Letters, 10(3), 284290. https://doi.org/10.17811/ebl.10.3.2021.284-290

Vuong, Q. H., \& Napier, N. K. (2014). Making creativity: the value of multiple filters in the innovation process. International Journal of Transitions and Innovation Systems, 3(4), 294-327. https://doi.org/10.1504/ijtis.2014.068306 